\title{
Smoking in movies in Australia: who feels over-exposed and what level of regulation will the community accept?
}

\author{
Christine L. Paul, Raoul A. Walsh, Fiona Stacey, Flora Tzelepis, Wendy Oakes and Anita Tang
}

Documented levels of smoking in movies increased during the 1990s, ${ }^{1}$ in contrast to levels of smoking in the US where many of the movies originate. ${ }^{2}$ Young people are more likely than older people to attend the movies, ${ }^{3}$ while high exposure to smoking in movies increases smoking uptake ${ }^{4}$ and progression to established smoking. ${ }^{5}$ Public health advocates in Australia concerned with levels of smoking in movies are calling for regulation to curb their harmful effects. ${ }^{6}$

There are no available data on community perceptions about the level of smoking in movies in Australia, and whether there is support for regulation. This study aimed to explore the following in NSW:

- exposure to excessive or inappropriate smoking in movies;

- perceptions of whether smoking in movies is excessive and the potential impetus for excessive or inappropriate smoking in movies;

- attitudes to regulating smoking in movies; and,
- demographic and smoking status predictors of exposure, perceptions and attitudes.

\begin{abstract}
Method
Households were selected at random from the NSW Electronic White Pages and mailed an information letter. One Englishspeaking adult member per household was selected at random to complete a computer-assisted telephone interview. Age, gender, and area of residence (Sydney/regional NSW) quotas were applied based on Census proportions (Appendix 1, survey items, is available from authors).
\end{abstract}

\section{Analysis}

Descriptive statistics and Chi-squares were used to describe perceptions and identify potential demographic and smoking status predictors of exposure, perceptions and attitudes.

\section{Abstract}

Objective: This study aimed to examine recent levels of exposure to smoking in movies, how the community perceived the level of smoking they saw in recently-viewed movies and whether there was community support for any form of regulation.

Methods: As part of a 2004 New South Wales survey of smoking-related perceptions and practices, 1,154 adults participated in a computer-assisted telephone interview about perceptions relating to smoking depiction in movies and television.

Results: More than one-quarter of those who had seen a recent movie in the cinema (28.5\%) or on DVD $(33.9 \%)$ thought that the movie contained excessive or inappropriate smoking. More than half the sample (59.1\%) considered it likely the tobacco industry played a role in the level of smoking depiction, although only $18 \%$ of those who thought a recent movie contained excessive smoking attributed this to the tobacco industry. Almost two-thirds of respondents favoured screening anti-tobacco advertisements prior to movies with smoking.

Conclusion: Cinema and DVD movies commonly include scenes where there is excessive or inappropriate smoking. It is widely believed that the tobacco industry is contributing to this, and there is strong community support for action to curb the harmful influences this may be having.

Key words: tobacco, smoking, movies, regulation, legislation

Health Promotion Journal of Australia 2008; 19:229-31

\section{So what?}

Movies are a domain where smoking is frequently depicted, and this may mitigate the benefits of tobacco control strategies. There should be a requirement for anti-tobacco advertisements prior to screening movies containing smoking. 


\section{Results}

\section{Sample}

Of the 12,000 telephone numbers identified in the sampling process, 3,503 gave complete interviews (response rate of $43 \%$ ) and 3,638 refused to participate (consent rate of $49 \%$ ). The prevalence of smoking (daily or occasional) in the study sample was $15.4 \%$ (raw unweighted data). Of the 3,503 participants, a random subsample of 1,154 completed the items on smoking in movies of which $15.7 \%$ were smokers.

\section{Recent exposure to smoking in movies}

At least half of the sample had viewed at least one movie at the cinema (53.3\%) in the previous three months. A similar proportion had viewed a new-release movie on video or DVD (55\%) within the previous month. A minority had seen more than two movies (22\% for cinema, 36\% for video/DVD). Those 18-29 years viewed more cinema movies than those over 50 years $($ mean $=2.4 \vee 1.4 ; p<0.0001)$. Given the low mean number of movies viewed, respondents may have been commenting on a small number of movies popular at the time.

Perceptions of whether smoking is excessive or inappropriate

Of those who had seen at least one cinema movie $(n=614)$ in the previous three months, 9.3\% reported all the recent movies they had seen contained excessive or inappropriate smoking. Of those who had seen at least one new release video or DVD $(n=630)$ in the previous month, $6.0 \%$ reported all the recent movies they had seen contained excessive or inappropriate smoking. Another $19.2 \%$ of cinema viewers reported at least one recent movie contained excessive or inappropriate smoking, while $27.9 \%$ of video/DVD viewers reported at least one recent movie contained excessive or inappropriate smoking.

For cinema viewers, reporting excessive or inappropriate smoking in movies was associated with younger age $\left(\chi^{2}=6.56\right.$, $\mathrm{df}=2, p<0.05)$, never being a smoker $\left(\chi^{2}=6.86, \mathrm{df}=2\right.$, $p<0.05)$ and not being born in Australia $\left(\chi^{2}=5.12, d f=1\right.$, $p<0.05)$. For video/DVD viewers, those reporting excessive or inappropriate smoking had higher levels of education $\left(\chi^{2}=7.39, \mathrm{df}=2, p<0.05\right)$ and were not born in Australia $\left(\chi^{2}=4.24, \mathrm{df}=1, p<0.05\right)$. Smokers who had made a quit attempt in the last two years were more likely than smokers who had not made a quit attempt to report excessive or inappropriate levels of smoking in recent video or DVD movies $(p<0.05$, Fisher's exact test).

\section{Perceptions regarding the potential impetus}

Those who thought that at least one movie, video, or DVD had excessive or inappropriate smoking $(n=278)$ gave reasons (see Table 1), with $17.9 \%$ reporting that that it was likely or very likely that tobacco industry involvement may have played a role in the amount of smoking in those movies. More than half of those who saw at least one movie (59.1\%) reported that it was likely/very likely that tobacco industry involvement played a role in the amount of smoking portrayed. Those reporting that the tobacco industry had a role in the amount of smoking in movies had higher levels of education $\left(\chi^{2}=6.83\right.$, $\mathrm{df}=2, p<0.05)$, and were more likely to be smokers who had tried to quit in the last two years $\left(\chi^{2}=11.12, \mathrm{df}=1, p<0.001\right)$, or smokers intending to quit within six months $\left(\chi^{2}=8.88\right.$, $\mathrm{df}=2, p<0.05)$.

Attitudes to regulation

All participants $(n=1154)$ were asked their attitude toward government regulation of smoking in movies. As shown in Table 2, 63.1\% of respondents agreed with introducing antismoking advertisements prior to movies containing smoking, while $37.2 \%$ supported the inclusion of smoking in the rating system.

Table 1: Perceived reasons for movies or DVDs containing excessive levels of smoking.

\begin{tabular}{lc}
\hline Perceived Reason & $\begin{array}{c}\text { Total }(\mathbf{n = 2 7 8})^{\mathbf{a}} \\
\mathbf{\%}\end{array}$ \\
\hline Important to the story, characters or setting & 37.1 \\
Product placement/cigarette companies paid for & 16.1 \\
their brand to be in the movie & 3.9 \\
Actors or actresses were smokers & \\
Film personnel (directors, producers, writers) thought & 2.9 \\
it was important to the story & 1.8 \\
Actor(s) had an agreement with cigarette company & 30.6 \\
Other & 14.3 \\
Don't know & \\
\hline Notes: & \\
(a) Only those who thought that one or more movies, videos, or DVDs had too much or \\
inappropriate smoking \\
(b) Person could give more than one response, so percentages add to more than 100\%. \\
\hline
\end{tabular}

Table 2: Attitudes toward potential governmental regulation of smoking in movies.

\begin{tabular}{lccc}
\hline & \multicolumn{3}{c}{ Total (n=1154) } \\
$\begin{array}{l}\text { Potential Government } \\
\text { Action }\end{array}$ & $\begin{array}{c}\text { Definitely } \\
\text { yes } \\
\text { \% }\end{array}$ & $\begin{array}{c}\text { Maybe/ } \\
\text { unsure } \\
\text { \% }\end{array}$ & $\begin{array}{c}\text { Definitely } \\
\text { not } \\
\text { \% }\end{array}$ \\
\hline $\begin{array}{l}\text { Screen anti-smoking ads } \\
\text { before movies that have any } \\
\text { smoking in them }\end{array}$ & 63.1 & 15.6 & 20.7 \\
$\begin{array}{l}\text { Regulate the movie industry to } \\
\text { limit the portrayal of smoking } \\
\text { in movies }\end{array}$ & & & \\
$\begin{array}{l}\text { Include smoking in the rating } \\
\text { system as they do for language } \\
\text { and violence }\end{array}$ & 50.7 & 17.9 & 30.8 \\
\hline
\end{tabular}




\section{Discussion}

The study data suggest that a substantial proportion of Australian adults experience exposure to tobacco promotion via movies. Younger age groups appear to be the most exposed, which is of concern given that early adulthood is a time when established smoking patterns develop. The study results are likely to be representative of community views about smoking in movies in terms of movies popular at the time.

Almost one-third (29\%) of those viewing cinema movies and $33.9 \%$ of those viewing movies on videos and DVDs reported that they had recently seen movies where the smoking was excessive or inappropriate. While there was no attempt to identify which movies participants had seen, there is no apparent bias in sample characteristics which would influence the types of movies viewed. It should be noted that the lack of data about the proportion of movies viewed which contained any smoking is a study limitation. Interpretation is also limited by the fact that the mean number of movies viewed was only two, as many respondents may have viewed the same small number of popular movies.

Perceptions about the reasons for excessive or inappropriate smoking indicate that smoking is often perceived as relevant to the plot, characters or setting. It is difficult to interpret whether this is due to the movies viewed or the respondents' perceptions without an analysis of the actual movies viewed.

With regard to regulation, almost two-thirds (63\%) of respondents favoured screening anti-tobacco advertisements prior to cinema movies containing smoking. Given that there is some evidence for the effectiveness of this strategy, ${ }^{6}$ the strong community support suggests regulators have a mandate to put such a regulation in place. The degree to which this regulation could be applied to videos and DVDs is limited, although producers such as Disney are moving in this direction.
An additional interesting finding relevant to smokers is that those who had tried to quit were more likely to report excessive or inappropriate smoking in movies, and to perceive that the tobacco industry plays a role in promoting smoking in movies. It may be that those who had tried to quit were particularly vulnerable to viewing smoking. Evidence regarding the effect of alcohol advertising on recovering alcoholics supports this view ${ }^{7}$ and reinforces the need to address smoking in movies.

Clearly there is a need to counterbalance the excessive levels of smoking movie viewers are exposed to. Mandatory screening of anti-tobacco advertisements prior to movies with smoking appears sensible given its potential effect and relative ease of implementation, and the strong community support that there is for such a move.

\section{Acknowledgements}

This project was undertaken under the auspices of The Cancer Council New South Wales' Centre for Health Research \& Psycho-oncology (CHeRP), with funding from The Cancer Council NSW and infrastructure support from Hunter Medical Research Institute.

\section{References}

1. Stockwell TF, Glantz SA. Tobacco use is increasing in popular films. Tob Control. 1997;6:282-4

2. Worth KA, Dal Cin S, Sargent JD. Prevalence of smoking among major movie characters: 1996-2004. Tob Control. 2006;15:442-6.

3. Mortimer D. Smoke-screens: Why tobacco companies are winning with the young. Medical Observer. 1998 March 20;46-7.

4. Sargent JD, Beach ML, Adachi-Mejia AM, Gibson JJ, et al. Exposure to Movie Smoking: It's Relation to Smoking Initiation. Pediatrics. 2005;116(5):118391.

5. Sargent JD, Worth K, Tanski SE, Dal Cin S, et al. Association between exposure to movie smoking and established smoking. Proceedings of the Pediatric Academic Societies' Annual Meeting; 2006 April 29-May 2; San Francisco, California.

6. Edwards CA, Harris WC, Cook DR, Bedford KF, et al. Out of the smokescreen: does an anti smoking advertisement affect young women's perception of smoking in movies and their intention to smoke. Tob Control. 2004;13:277-82.

7. Casswell S. Does alcohol advertising have an impact on the public health? Drug Alcohol Rev. 1995;14:395-404.

\section{Authors}

Christine L. Paul, Raoul A. Walsh, Fiona Stacey, Flora Tzelepis, Centre for Health Research \& Psycho-oncology (CHeRP), The Cancer Council NSW, The University of Newcastle, Hunter Medical Research Institute, New South Wales

Wendy Oakes, Anita Tang, The Cancer Council New South Wales

Christine Paul, Centre for Health Research \& Psycho-oncology (CHeRP), Locked Bag No. 10, Wallsend NSW, Australia, 2287. Fax: 024913 8779; e-mail Chris.Paul@newcastle.edu.au 